Volume 3, No. 1

Jan - Mar 2018
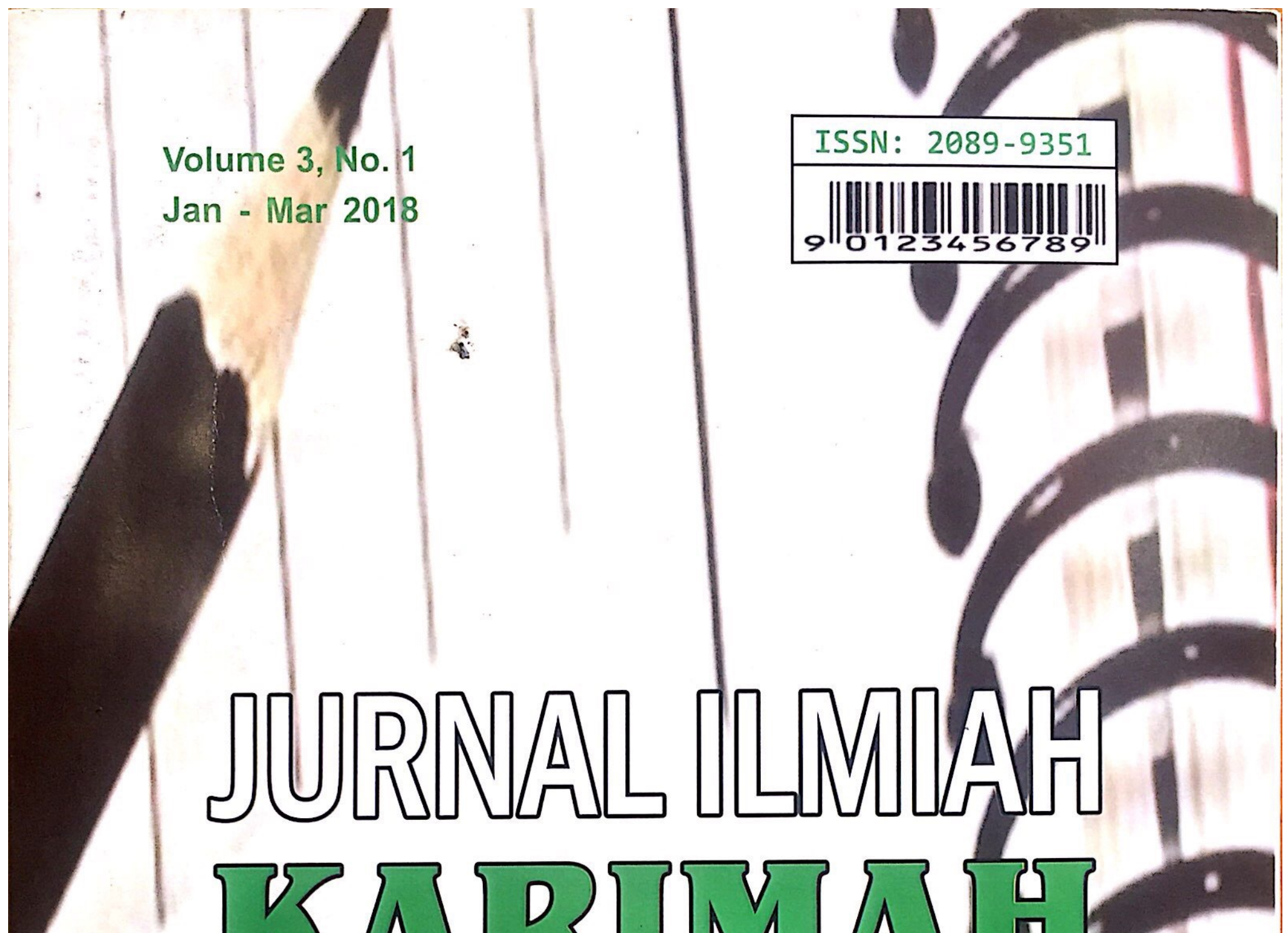

ISSN: 2089-9351
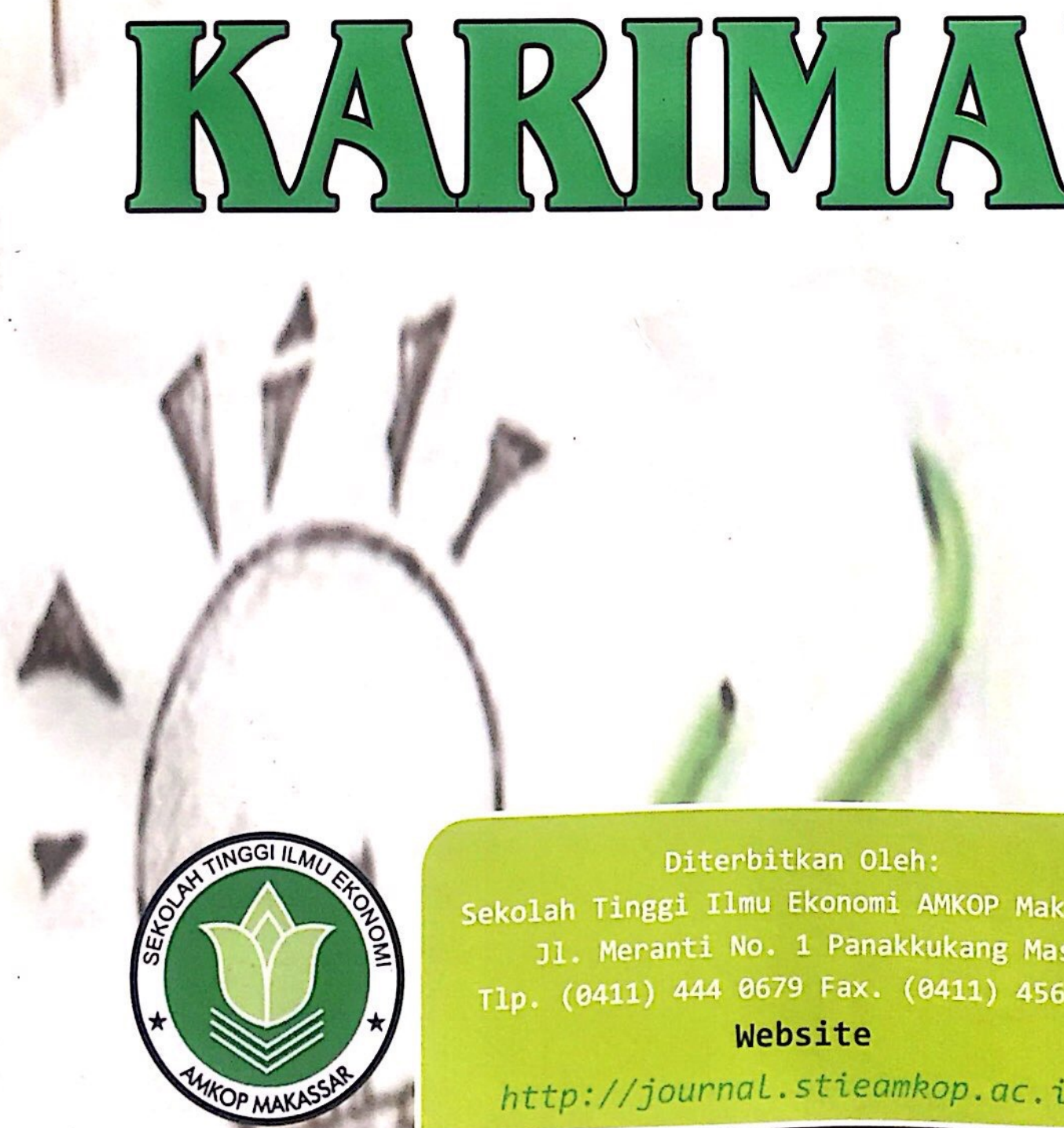

Diterbitkan 01eh:

Sekolah Tinggi IImu Ekonomi AMKOP Makassan j1. Meranti No. 1 Panakkukang Mas Tlp. (8411) 4448679 Fax. (6411) 456965 Website http://journal.stieamkop.ac.id/ 
Dewan Redaksi

Abdul Karim (Ketua)

Sofyan Hamid (Anggota)

Firdaus (Anggota)

Dedi Miswar (Anggota)

Mitra Bestari

H. Mursalim Umar Gani

H. Matalatta

H. Gunawan Bata Ilyas

H. Zainuddin Rahman

\section{Editor Pelaksana: \\ Abdul Karim \\ Firdaus \\ Andi Hidayat \\ Sofyan Hamid}

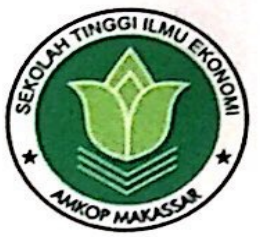

KARIMAH Jurnal Ilmiah

Sekolah Tinggi Ilmu Ekonomi (STIE)

AMKOP Makassar

Alamat Redaksi

Jalan Meranti No. 1 Panakkukang Makassar

Lantai 1 Gedung C STIE Amkop

Website

http://journal.stieamkop.ac.id/ 


\section{JURNAL ILMIAH KARIMAH STIE AMKOP MAKASSAR}

\section{DAFTAR ISI}

Halaman

Editorial

Daftar Isi

Pengaruh Motivasi Kerja Terhadap Kepuasan Kerja Pegawai Negeri Sipil (PNS)

Di Kantor Sekretariat Daerah Kota Tarakan

(Eli Hasmin)

$444-449$

Analisis Pengaruh Kepemimpinan Dan Komitmen Kerja Terhadap Peningkatan

Kinerja Karyawan Pada NV. Hadji Kalla Di Makassar $\quad$ (Muh. Dedi Miswar) $\quad 450-459$

Pengaruh Kepemimpinan, Kompensasi, Disiplin Kerja Terhadap Kinerja Pegawai Kantor PD. Pasar Raya Kota Makassar

(Mansur Azis)

$460-473$

Pengaruh Motivasi Kerja Terhadap Prestasi Kerja Agen Asuransi Pada

PT. Zurich Topas Life Cabang Galaxy Makassar

(H. Umar)

$474-483$

Pengaruh Persepsi Kemudahan, Kebermanfaatan, Dan Minat Perilaku Terhadap Intensitas Penggunaan E-Filing Di Kantor Pelayanan Pajak Pratama Merauke (Muhammad Chalik Nurzam \& Mursalim)

Peran Strategi Manajer Dalam Manajemen Sumber Daya Manusia (Johan Zainuddin) $497-506$

Analisis Penerapan PSAK Nomor 46 Pada Laporan Keuangan PT. Rachmat Delapan Putera (Andi Lutfi) $507-517$

Pengaruh Modernisasi Sistem Administrasi Perpajakan Terhadap Kepatuhan Wajib Pajak Badan Pada Kantor Pelayanan Pajak Pratama Makassar Utara (Edy Susanto)

$518-527$

Tingkat Kepatuhan Wajib Pajak Di Kantor Pelayanan Pajak Makassar Utara (Muhammad Arsyad)

Analisis Kebutuhan Modal Kerja Terhadap Profabilitas Pada PT. Internasional Nickel Indonesia Tbk (Athaillah) 


\title{
PENGARUH MOTIVASI KERJA TERHADAP KEPUASAN KERJA PEGAWAI NEGERI SIPIL (PNS) DI KANTOR SEKRETARIAT DAERAH KOTA TARAKAN
}

\author{
Eli Hasmin \\ STIEM Bongaya Makassar \\ email: elihasmin56@gmail.com
}

\begin{abstract}
Abstrak
Jenis penelitian adalah penelitian survei, sehingga ditemukan kejadian-kejadian dan hubungan antar konstruk. Populasi penelitian pegawai Setda Kota Tarakan berjumlah 195 orang, seluruhnya dijadikan sampel (sampel jenuh). Teknik pengumpulan data menggunakan kuesioner dan dianalisis secara deskriptif dan inferensial dengan menggunakan The Structural Equation Modeling (SEM) dari paket software statistik Lisrel dan Confirmatory Factor Analysis (CFA).

Hasil penelitian menunjukkan bahwa motivasi kerja berpengaruh secara langsung terhadap kepuasan kerja pegawai di kantor Setda Kota Tarakan.
\end{abstract}

Kata kunci: Motivasi Kerja dan Kepuasan Kerja Pegawai Negeri Sipil (PNS).

\section{Abstract}

This type of research is a research survey, so that found incidents and relationships between invalid constructs. Population research officer of Setda Tarakan numbered 195 people, entirely made of samples (samples saturated). Engineering data collection using a questionnaire and analyzed are descriptive and inferensial by using The Structural Equation Modeling (SEM) of Lisrel statistical software packages and Confirmatory Factor Analysis (CFA).

The results showed that the motivation of working directly against the influential job satisfaction employees in the offices of Setda Tarakan.

Keywords: Work Motivation and job satisfaction civil servant (PNS).

\section{PENDAHULUAN}

\section{A. Latar Belakang}

Berlakunya UU No. 5 Tahun 2014 tentang Aparatur Sipil Negara (ASN) dan UU No. 23 Tahun 2014 tentang Pemerintahan Daerah, seharusnya mendorong pegawai Setda Kota Tarakan melaksanakan pekerjaannya dengan baik. Namun faktanya mengisyaratkan rendahnya kepuasan kerja pegawai, yang ditengarai karena rendahnya motivasi kerja. Hal ini tercermin pada perilaku mereka yang melakukan aktivitas yang tidak ada hubungan dengan pekerjaan, hanya check lock saat masuk dan check lock saat pulang, serta masuk dan pulang tidak tepat waktu (masuk lambat dan pulang cepat).

Motivasi kerja sangat penting dalam upaya meningkatkan kepuasan kerja pegawai. Rendahnya motivasi kerja yang diterima pegawai akan mempengaruhi kepuasan mereka dalam menjalankan tugas-tugas birokrasi, pembangunan dan pelayanan yang profesional kepada masyarakat. Pegawai perlu diberi motivasi kerja yang tinggi, agar mereka lebih puas dan bersemangat dalam bekerja (Aditya, 2011:38). Pemberian motivasi harus diarahkan dengan baik menurut prioritas dan dapat diterima dengan baik oleh seluruh 
pegawai, karena motivasi tidak dapat diberikan untuk setiap pegawai dengan bentuk yang berbeda-beda (Sujak, 1990 dalam Ermayanti, 2001:71).

Pegawai menyadari bahwa motivasi kerja merupakan salah satu faktor pendorong kepuasan kerja di lingkup Setda Kota Tarakan, tetapi faktanya belum dimplementasikan. Rendahnya kepuasan kerja pegawai diidentifikasi sebagai akibat kurang motivasi. Kepuasan kerja timbul karena faktor motivasi kerja. Semakin tinggi motivasi kerja yang dirasakan oleh pegawai. semakin tinggi pula kepuasan kerja (Brahmasari, 2008:96). Penclitian yang relevan dengan penelitian ini adalah : motivasi kerja berpengaruh positif dan signifikan terhadap kepuasan kerja (Suparman, 2007:90).

Berdasarkan latar belakang dan fakta lapang. peneliti tertarik mengkaji tentang "Pengaruh Motivasi Kerja Terhadap Kepuasan Kerja Pegawai Negeri Sipil (PNS) di Kantor Sekretariat Daerah Kota Tarakan".

\section{B. Rumusan Masalah}

Apakah motivasi kerja berpengaruh langsung terhadap kepuasan kerja pegawai di kantor Setda Kota Tarakan ?

\section{Tujuan Penelitian}

Untuk menganalisis dan mengetahui pengaruh motivasi kerja terhadap kepuasan kerja pegawai di kantor Setda Kota Tarakan.

\section{TINJAUAN PUSTAKA}

\section{A. Motivasi Kerja}

Motivasi kerja yang cukup terkenal adalah teori motivasi dua faktor yang dikembangkan Herzberg (1966) dalam S.P.Siagian (2004:89). Kedua faktor tersebut yang mempengaruhi kondisi pekerjaan seseorang yaitu motivasi instrinsik adalah daya dorong yang timbul dari dalam diri setiap orang seperti

keberhasilan, pengakuan/penghargaan, pekerjaan itu sendiri, tanggung jawab.

pengembangan.

\section{Menurut}

Herzbers

ekstrinsik tidak akan mendoroy pegawai untuk berforma baik, teta, dapat menjadi sumber ketidakpuas.. potensial. Untuk itu jika membs motivasi. yang perlu diperhatih. terlebih dahulu adalah faktor-fakm instrinsik. Motivasi instrinsik memilh beberapa indikator sebagai berikut:

1. Keberhasilan, Pencapaian presta (achievement) dalam melakuhat pekerjaan akan menggerakkan yang bersangkutan untuk melakukan tuga berikutnya, timbuln sikap positif dan ingin melakukan pekerjaan yans menantang sebagai suatu pendorons untuk mencapai sasaran.

2. Pengakuan/penghargaan terhadap prestasi merupakan motivasi yang cukup ampuh. bahkan bisa melebih kepuasan yang bersumber dan pemberian kompensasi.

3. Pekerjaan itu sendiri, Pekerjaan akan disenangi oleh seseorang bila pekerjaan itu sesuai kemampuan dan menantang, pekerjaan yang kurans disenangi dan tidak menantang. tidak menjadi pendorong. bahkin membosankan.

4. Tanggung jawab, Setiap pegawa ingin dipercaya memegang tanggun! jawab yang lebih besar baik tanggung jawab atas pekerjaan. maupun tanggung jawab berup: kepereayann yang diberikan sebaga orang yang mempunyai potensi.

5. Pengembangan, Setiap pegawa! menghendaki kemajuan atau perubahan dalam pekerjaannya, tidak hanya dalam jenis pekerjaan yan! berbeda atau bervariasi, tetapi jug: dalam posisi yang lebih bait (promosi) (Herzberg dalam Siagian 204:166).

\section{B. Kepuasan Kerja.}

Kepuasan kerja sebagai suatl sikap umum seorang individu terhada! 
pekerjaannya. Pekerjaan menuntut interaksi dengan rekan sekerja dan atasan, mengikuti aturan dan kebijakan organisasi, memenuhi standar kinerja, hidup pada kondisi kerja yang sering kurang dari ideal, dan hal serupa lainnya (Robbins, 2007:107). Kepuasan kerja terdiri dari lima aspek atau indikator (Robbins, 2007:145) yaitu:

1. Kepuasan pada pekerjaan itu sendiri (Satisfaction with the Work Itself). Orang yang kepribadiannya kongruen (sama dan sebangun) dengan pekerjaan yang mereka pilih, mempunyai bakat dan kemampuan yang tepat untuk memenuhi tuntutan dari pekerjaan mereka.

2. Kepuasan pembayaran (Satisfaction with Pay). Kepuasan pada pembayaran merupakan hal yang bersifat multi dimensional, ini berarti bahwa kepuasan karyawan bukan hanya terletak pada jumlah gaji/upah semata, namun lebih dari itu.

3. Kepuasan pada promosi (Satisfaction with Promotion). Kesempatan untuk dipromosikan

memberikan kepuasan kepada karyawan. Promosi bisa dilakukan berdasarkan senioritas dan kinerja.

4. Kepuasan pada supervisi (Satisfaction with

Supervision). Supervisi merupakan salah satu hal yang cukup penting sebagai sumber kepuasan kerja, hal ini berkaitan dengan gaya kepemimpinan.

5. Kepuasan pada rekan kerja (Satisfaction with Coworkers). Rekan kerja menjadi sumber kepuasan, manakala antar karyawan diberi kesempatan untuk berinteraksi satu sama lain, jika kesempatan yang diberikan untuk berkomunikasi hanya sedikit, maka kepuasan mereka rendah dan cenderung terjadi turn over (Feldman \& Arnold, 1983 dalam Zoel, 2011:107).

\section{Hipotesis}

Motivasi kerja berpengaruh terhadap kepuasan kerja di Kantor Setda Kota Tarakan.

\section{METODE PENELITIAN}

A. Jenis dan Lokasi Penelitian

Menurut pendekatan, penelitian ini termasuk jenis penelitian survei sehingga ditemukan kejadian dan hubungan antar konstruk yaitu mencari hubungan kausal antara satu konstruk dengan konstruk lain. Penelitian dilaksanakan di Kantor Setda Kota Tarakan Jalan Kalimantan No.1 Tarakan.

\section{B. Pendekatan Penelitian}

Penelitian ini adalah kuantitatif dengan pendekatan survei (korelasional), yaitu menggunakan kuesioner sebagai alat pengumpulan data. Pendekatan penelitian ini menggambarkan desain penelitian di mana semua konstruk memiliki korelasi.

\section{Populasi dan Sampel}

Populasi dalam penelitian ini adalah keseluruhan pegawai (PNS) yang ada pada kantor Setda Kota Tarakan berjumlah 195 orang. Distribusi populasi berdasarkan job/bagian yaitu Pemerintahan 69 orang, Ekbang 44 orang, Kesra 34 orang, dan Bagian Adum 48 orang. Seluruh populasi dijadikan sampel penelitian (sampel jenuh). 
HASIL PENELITIAN DAN PEMBAHASAN

A. Deskripsi Responden

\begin{tabular}{|c|c|c|c|c|}
\hline No & Menurut Umur & Frekuensi & Persentase & $\%$ Kumulatif \\
\hline 1 & $\leq 30$ & 65 & 33,33 & 33,33 \\
\hline 2 & $31-40$ & 65 & 33,33 & 66,66 \\
\hline 3 & $41-50$ & 52 & 26,67 & 93,33 \\
\hline \multirow[t]{2}{*}{4} & $\geq 50$ & 13 & 6,67 & 100 \\
\hline & Jumlah & 195 & 100 & 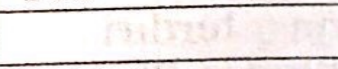 \\
\hline No & Menurut Jenis Kelamin: & & & \\
\hline 1 & Laki-laki & 109 & 55,90 & 55,90 \\
\hline \multirow[t]{2}{*}{2} & Perempuan & 86 & 44,10 & \\
\hline & Jumlah & 195 & 100 & 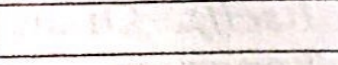 \\
\hline No & Menuru Job/Bagian: & & & \\
\hline 1 & Pemerintahan & 69 & 35,38 & 35,38 \\
\hline 2 & Ek. \& Pembangunan & 44 & 22,56 & $\begin{array}{l}57,94 \\
75,28\end{array}$ \\
\hline 3 & Kesejahteraan Rakyat & 34 & 17,44 & 75,38 \\
\hline \multirow{2}{*}{4} & Administrasi Umum & 48 & 24,62 & 100 \\
\hline & Jumlah & 195 & 100 & \\
\hline No & Menuru Pendidikan: & & & \\
\hline 1 & SMP Sederajat & & & 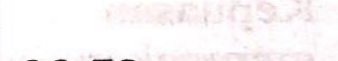 \\
\hline 2 & SMA Sederajat & 56 & 28,72 & 28,72 \\
\hline 3 & Diploma & 55 & 28,20 & 56,92 \\
\hline 4 & Starata Satu (S.1) & 78 & 40,00 & 96,92 \\
\hline 5 & Starata Satu (S.2) & 6 & 3,08 & 100 \\
\hline \multirow[t]{2}{*}{6} & Strata Tiga (S3) & - & - & 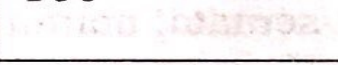 \\
\hline & Jumlah & 195 & 100 & E \\
\hline No & MenuruPangkat/Gol.: & & & \\
\hline 1 & Pangkat/Golongan I & 1 & 0,52 & 0,52 \\
\hline 2 & Pangkat/Golongan II & 79 & 40,51 & 41,03 \\
\hline 3 & Pangkat/Golongan III & 100 & 51,28 & 92,31 \\
\hline \multirow[t]{2}{*}{4} & Pangkat/Golongan IV & 15 & 7,69 & 100 \\
\hline & Jumlah & 195 & 100 & \\
\hline No & Masa Kerja & & & \\
\hline 1 & $\leq 10$ & 78 & 40,00 & 40,00 \\
\hline 2 & $11-15$ & 48 & 24,62 & 64,62 \\
\hline 3 & $16-20$ & 32 & 16,41 & 81,03 \\
\hline 4 & $21-25$ & 26 & 13,33 & 94,36 \\
\hline \multirow[t]{2}{*}{5} & $\geq 25$ & 11 & 5,64 & 100 \\
\hline & Jumlah & 195 & 100 & \\
\hline
\end{tabular}

Sumber : Data Primer diolah.

B. Pengaruh Motivasi Kerja Secara Langsung Terhadap Kepuasan Kerja

Motivasi kerja pada penelitian ini difahami sebagai suatu dorongan yang muncul dari dalam diri seseorang untuk melakukan suatu pekerjaan dalam rangka memenuhi keinginan atau kebutuhannya.

Hipotesis dalam penelitian ini adalah motivasi kerja berpengaruh secara langsung terhadap kepuasan kerja.

Hipotesis statistik:

$\mathrm{H}_{0}: \mathrm{P}_{\mathrm{y} 12 \mathrm{X}_{2}} \leq 0$

$\mathrm{H}_{1}: \mathrm{P}_{\mathrm{y} 12 \mathrm{X}_{2}}>0$

Hasil analisis diperoleh nilai koefisien jalur $\mathrm{P}_{\mathrm{y} 12 \mathrm{X} 2}=0.85807$ dengan 
nilai t-hitung $=6.13438$. Nilai pada $\mathrm{t}$ tabel dengan tingkat signifikansi 0,05 dengan jumlah responden $(n)=195$ diperoleh angka t-tabel $=1,97$ (lampiran 8) sehingga t-hitung $>$ t-tabel $(6.13438$ $>1,97)$, maka tolak $\mathrm{H}_{0}$ dan terima $\mathrm{H}_{1}$.

Hasil analisis koefisien pengaruh langsung antar variabel (standarized solution) tersebut, menunjukkan bahwa motivasi kerja berpengaruh secara langsung terhadap kepuasan kerja, yang berarti hipotesis terbukti. Hasil penelitian ini, tidak terlepas dari peranan kepemimpinan Walikota Tarakan dalam memotivasi pegawai melalui penerapan teori motivasi, seperti memberikan job sesuai dengan kemampuan (kompetensi), mengakui/menghargai prestasi pegawai, memberi tanggung jawab, kepercayaan dan peluang untuk berkembang baik jenis pekerjaan maupun posisi.

Pernyataan ini relevan dengan teori yang menyatakan bahwa tidak ada motivasi jika tidak dirasakan kebutuhan dan kepuasan kerja. Motivasi bawahan, yang diperhatikan terlebih dahulu adalah faktor-faktor yang menimbulkan rasa puas yaitu instrinsik (Herzberg, 2005 dalam Siagian, 2004:166).

Pentingnya motivasi kerja terhadap kepuasan kerja didukung oleh penelitian Brahmasari dan Suprayetno (2008) dan Suparman (2007), masingmasing menyimpulkan bahwa motivasi kerja berpengaruh positif dan signifikan terhadap kepuasan kerja.

\section{SIMPULAN}

Berdasarkan pembahasan yang dikemukakan di atas, maka disimpulkan bahwa motivasi kerja berpengaruh secara langsung terhadap kepuasan kerja pegawai di kantor Setda Kota Tarakan (hipotesis diterima).

\section{DAFTAR PUSTAKA}

Aditya, T. 2011. Pengaruh Motivasi Kerja, Kepemimpinan dan Budaya Organisasi terhadap Kepuasan Kerja serta Dampaknya pada Komitmen
Agen Asuransi. (Studi Kasus: PT Synergi Adhi Manunggal). Surabaya: Jurnal Manajemen Vol.5 No.1 UPN, Surabaya.

Arikunto, S. 2006. Prosedur Penelitian:

Suatu Pendekatan Praktis. Jakarta: Rineka Cipta.

Brahmasari, \& Suprayetno, 2008.

Pengaruh Motivasi Kerja,

Kepemimpinan dan Budaya

Organisasi terhadap Kepuasan Kerja Karyawan serta Dampaknya pada Kinerja Perusahaan (Studi Kasus PT. Pei Hai Internasional Wiratama Indonesia).

Ermayanti, D. \& Thoyib, A. 2001. Pengaruh Faktor Motivasi terhadap Prestasi Kerja Karyawan pada Kantor Perum Perhutani Unit II Surabaya. Malang: Fakultas Ekonomi Universitas Brawijaya.

Ferdinand,A.2000. Structural Equation Modeling Dalam Penelitian Manajemen. Semarang: Badan Penerbit Undip.

Ghozali, 2005, Model Persamaan Struktural Konsep dan Aplikasi Dengan Program AMOS Ver.5. Semarang: Badan Penerbit Undip.

Robbins, S.P. 2007. Perilaku Organisasi : Buku Jakarta: Salemba Empat.

Siagian, 2006. Organisasi, Kepemimpinan dan Perilaku Administrasi. Jakarta: Gunung Agung.

Sugiyono. 2007. Metode Penelitian Administrasi. Bandung: Alfabeta.

Suparman. 2007. Analisis Pengaruh Peran Kepemimpinan, Motivasi dan Komitmen Organisasi terhadap Kepuasan Kerja Dalam Meningkatkan Kinerja Pegawai (Studi Pada Pegawai Di Lingkungan Pemerintah 
Daerah Kabupaten Sukamara

Di Propinsi Kalimantan

Tengah).Tesis. Semarang:

Undip Semarang.

Sutrisno, H. 2003. Metodologi Penelitian : Yogyakarta: BPFE UGM.

Undang-Undang Republik Indonesia Nomờ 5 Tảhün 2014 tentang Aparatur Sipil Negara. Jakarta: Citra Umbara.

Undang-Undang Republik Indonesia Nomor 23 Tahun 2014 tentang Pemerintahan Daerah.

Zoel, D. R. 2011. Pengertian, Manfaat, Efek dan Faktor-faktor yang Mempengaruhi Kepuasan Kerja, http://www.zoeldhan infomanajemen.com/ 2011/11, Diakses November 2011. 